\title{
Of Blooming Flowers and Multiple Sockets: The Role of Metaphors in the Politics of Infrastructural Work
}

\author{
Marcello Aspria \\ Department of Health Policy and Management, Erasmus University Rotterdam / aspria@bmg.eur.nl \\ Marleen de Mul \\ Department of Health Policy and Management, Erasmus University Rotterdam \\ Samantha Adams \\ Tilburg Institute for Law, Technology, and Society, Tilburg University \\ Roland Bal \\ Department of Health Policy and Management, Erasmus University Rotterdam
}

\begin{abstract}
We explore the role of two metaphors for innovation and infrastructure integration in the development of a regional patient portal. Our premise is that metaphors have real consequences for agenda setting and decision-making; we view them as operationalizations of sociotechnical imaginaries. Drawing on our formative study of the portal project, we focus on the generative character of metaphors and argue that they are constitutive elements of information infrastructures. While the two metaphors in our study helped to make imaginaries of 'integrated' and 'personalized' health care more definite, cognizable, and classifiable, they also concealed the politics of infrastructural work. We argue that the act of 'spelling out' metaphors can open up a space for new imaginaries and alternative strategies. With this study we aim to contribute to existing knowledge about infrastructural work, and to renew the interest among STS scholars for the role of discursive attributes in information infrastructures.
\end{abstract}

Keywords: metaphors, e-Health, information infrastructures

\section{Introduction}

Information infrastructures (IIs) emerge in different ways, and take on different shapes and forms in different domains. In health care, questions regarding the expansion and governance of Ils are increasingly pertinent, as the rapid differentiation of e-Health technologies and changing expectations about health communication go hand in hand with new practices, strategies, 
and policy agendas. Health care organizations and governmental bodies across the world seek to counter problems of 'fragmentation' in health information exchange (HIE), professing aims of increased quality and efficiency through various types of 'integrated' and 'personalized' solutions (cf. Detmer et al., 2008). Online health portals are frequently championed as vehicles of integrated HIE; although examples of portals that "fully intermediate the patient-provider relationship" are still scarce (Baird \& Nowak, 2014: e2), new socalled 'patient portal' initiatives abound. In the Netherlands, several attempts have been made to develop patient portals with a regional scope (De Mul et al., 2013). These initiatives varied greatly in terms of their professed objectives and ambitions, as well as in the complexity of their organizational and political contexts. A recent comparative study between three Dutch cases illustrates the difficulties of achieving implementation, technical interoperability, regulatory compliance, and financial sustainability; these challenges are especially tough in decentralized, highly heterogeneous networks of interdependent actors (Otte-Trojel et al., 2015).

Taking a closer look at how patient portals are developed in such a complex setting can yield useful insights in the sociotechnical makeup of Ils for health care, as well as in the infrastructural work (Star \& Ruhleder, 1996; Hanseth et al., 1996) that 'integrated' and 'personalized' systems in e-Health require. The concept of infrastructural work can designate a wide range of practices in the development and maintenance of infrastructures, all of which entail "political, ethical, and social choices" (Bowker et al., 2010: 99). In the context of patient portal development, we view infrastructural work as pertaining to the negotiation, classification, standardization, and translation of novel ideas about lls for health care. This work - which can take place in boardrooms, at project meeting tables, and on conference floors, as well as in a secluded computer lab or in the coffee room of a nursing home - is inextricably linked with the use of metaphors. In this paper we explore the use of metaphors by project members and stakeholders in the early development of a regional patient portal in the Netherlands, with the aim to unravel their role in the politics of infrastructural work.

There is a substantial body of literature in science and technology studies (STS) on practices in the design and development of Ils - generally with the aim to understand how science and technology themselves are produced (Monteiro, 2001: 74) - and several scholars have paid attention to the role of language and discursive attributes in those processes (Walsham, 1991; Hirschheim \& Newman, 1991; Monteiro \& Hepsø, 2002). With this paper we aim to contribute to that body of knowledge. We contend that discursive attributes can have tangible and far-reaching consequences for emerging Ils, and that exploring their use can help us to understand how e-Health agendas are shaped, therewith creating "a space for observation, comment and analysis" about alternative strategies (Woolgar \& Neyland, 2013: 7). To elaborate our argument we describe the use of two metaphors for innovation and infrastructure integration in a Dutch patient portal project: third party e-Health initiatives as 'blooming flowers', and the portal as a 'multiple socket'.

We argue that metaphors are constitutive elements of IIs and powerful attributes in infrastructural work: rather than acting as neutral or 'innocent' descriptors of abstract concepts, they can generate new realities by reconfiguring the imagined order of technologies, infrastructures, and their users, and by actively contributing to the manner in which choices are made in relation to architectures, standards, and classification systems. The novelty of our approach is that we view metaphors as operationalizations of sociotechnical imaginaries, which in our study consist of promises, hopes, goals, and expectations about 'integrated' and 'personalized' health care in a regional context. By reflecting on the consequences that metaphors can bear for agenda-setting and decision-making processes, we cast new light on how language and discursive attributes are tied into infrastructural work in emerging Ils. We thus hope to contribute to current knowledge about the politics of infrastructural work, and to renew the interest among STS scholars for discursive attributes in Ils. 


\section{Case Description and Research Questions}

Our study draws on ethnographical data collected during the early development of Zorgportaal Rijnmond (ZPR), ${ }^{1}$ an online portal for health care and wellbeing in the Rotterdam Rijnmond region of the Netherlands. A consortium of public and private partners carried out the development of the portal, and a Regional Health Information Organization (RHIO) acted as secretary of the project. We studied and actively contributed to the development of ZPR; our approach can be characterized as a form of action-oriented, engaged scholarship (Bal \& Mastboom, 2007; Mathiassen \& Nielsen, 2008; Zuiderent-Jerak, 2015). In our role as 'formative researchers' we were fascinated by the widespread use of metaphors among project members in designating technologies, practices, and processes. The idea of paying close attention to metaphors ensued from our own disconcertment (cf. Verran, 2001: 1-20), as we often struggled to 'spell them out' or to make sense of them analytically. The blooming flowers and multiple socket metaphors struck us as remarkably playful terms, seemingly contrasting with the serious ambitions that the project embodied.

We singled out these two metaphors as they became prevalent attributes of innovation and integration narratives in the early stage of the project. For this paper we formulated the following research questions: how did the enactments of the blooming flowers and multiple socket metaphors sustain the promises, hopes, goals, and expectations in the project? What did these enactments reveal and conceal in terms of the politics of infrastructural work? And consequently, how can an analysis of discursive attributes contribute to the study and development of Ils?

\section{The Generative Character of Metaphors in Infrastructural Work}

Since the early 1980s, scholars from various disciplinary backgrounds have studied the social and organizational dimensions of infrastructures in informatics and computing (Kling \& Scacchi, 1982; Kling, 1987; Bishop \& Star, 1996). STS scholars in particular made noteworthy contributions by theorizing the relational character of information infrastructures (IIs) (Bowker \& Star, 2000; Ellingsen \& Røed, 2010; Jæger \& Monteiro, 2005; Lampland \& Star, 2009; Star \& Ruhleder, 1996), which became increasingly relevant with the expansion of the World Wide Web and online technologies in the 1990s. In the context of health care, efforts to make visible the ongoing infrastructural work in Ils led them to focus on the implications and consequences of standards and standardization, the tension between local and global practices, and the politics and work involved in collaborations, alliances, and partnerships in e-Health (Bansler \& Kensing, 2010; Bjørn \& Kensing, 2013; Hanseth \& Ljungberg, 2001; Hanseth et al., 1996).

The use of metaphors in information technologies has been researched from various disciplines as well. Covering a wide range of theoretical perspectives, scholars addressed the relevance of metaphors in the design of computer systems (Carroll \& Thomas, 1982; Lanzara, 1983; Carroll \& Mack, 1985; Carroll et al., 1988; Andersen \& Madsen, 1988; Madsen, 1989; Greenbaum \& Kyng, 1991; Friedman, 1998), their use in the social construction of Internet imaginaries (Wyatt, 2004), their organizing role in information systems (IS) (Walsham, 1991; Hirschheim \& Newman, 1991; Monteiro \& Hepsø, 2002; Ellingsen \& Monteiro, 2008; Gillespie, 2010; Constantinides, 2013), and their enabling and constraining effects in Ils (Star \& Ruhleder, 1996; Monteiro \& Hepsø, 2002).

Our focus on the role of metaphors in lls builds on this body of work. We contend that their use is inextricably linked to infrastructural work, and that it can have far-reaching consequences for processes of agenda-setting and decision-making. Our basic premise is that metaphors structure our understanding of the world, and that they shape expectations in social interaction (Lakoff \& Johnson, 1980). We side with Schön's (1996) argument that metaphors can enable or constrain problem definitions in policy making, and adopt his notion of 'generative metaphor' to contend that the use of metaphors (and the implied act of 'spelling out' their meaning) has real technical and organizational implications for infrastructural work. In his view, metaphors refer "both to a certain kind of product - a perspective or frame, a way of looking at things - and to a certain kind of process - a process by which new perspectives 
on the world come into existence" (Schön, 1996: 137). Rather than serving as 'innocent' or neutral analogies, metaphors create new realities by contributing to the manner in which problems are formulated - and consequently, how solutions are envisioned.

Taking Schön's explanation as our point of departure, we regard metaphors not merely as linguistic reflections of a given social context, but as constitutive attributes in practices and knowledge production: they act as 'mobilization devices' that allow ideas to circulate (faster) and that influence the way in which people argue and convince each other (Latour, 1990: 31; Czarniawska-Joerges \& Joerges, 1992, 1996). Through their circulation in networks, metaphors affect a growing number of actors - such as the project managers, developers, policy makers, and other stakeholders in our study - and have the potential to (re)configure people, ideas, resources, and technologies. Like material objects, metaphors are 'enacted' in different ways in continuously changing settings. Following the example of Winthereik (2010), who discussed three enactments of systems development in an IT implementation project, we explore how the blooming flowers and multiple socket metaphors were enacted during the early stages of the ZPR project, and how this affected the development of the portal. Our focus on enactment allows us to move away from a strictly representational conceptualization of language (Leonardi \& Rodriguez-Lluesma, 2012) and to locate the meaning of metaphors in the act of speaking, rather than in "the object for which the word stands" (Wittgenstein, 2009:5e). Metaphors thus become part and parcel of a recursive process of ontological constitution (Woolgar \& Neyland, 2014: 38).

We view metaphors as operationalisations of sociotechnical imaginaries: they make the latter more discernible while leaving room for ambiguities and interpretative flexibility (Bijker et al., 2012: 20). We borrow the concept of sociotechnical imaginaries from Jasanoff \& $\operatorname{Kim}(2009,2013)$ to designate collective images and ideas of a future that is deemed at once attainable and necessary to be attained; the empirical case in our paper entails visions of 'personalized' and 'integrated' online health care in a regional context. Rather than treating imaginaries as mere reflections and representations of prospective technologies (cf. Marcus, 1995; Fortun \& Fortun, 2005) we regard them as expressions of social order that "prescribe futures" (Jasanoff \& Kim, 2009: 120) while being "constituent of the very situation of any doing or action" (Verran, 2001: 37). This conceptualization of imaginaries bears similarities to the notion of 'anticipation work' in Computer-Supported Cooperation Work (CSCW), which serves as a "frame to capture practices in the present that cultivate our expectations of the future" (Steinhardt \& Jackson, 2015). While the latter's aim is to make 'forwardthinking practices' visible, sociotechnical imaginaries foreground processes of agenda setting; these imaginaries also encompass metaphors that can be "used to call for action in the here and now" (Bijker et al., 2009: 105).

We view our theoretical argument as complementary to existing studies on the development of IIs in IS and CSCW literature, and with studies on the development and implementation of e-Health infrastructures in particular (Ellingsen \& Monteiro, 2003, 2006; Jæger \& Monteiro, 2005; Ellingsen \& Røed, 2010; Sahay et al., 2009; Aanestad \& Jensen, 2011; Ellingsen et al., 2013). We adopt a similar approach to interdependencies between material and non-material actors to focus on the work that is required for infrastructure integration in e-Health.

\section{Research Setting and Methods}

We conducted ethnographical research during the early development stage of Zorgportaal Rijnmond (ZPR). Our researchers' role in the project was to evaluate the design, development, and implementation of ZPR, as well as the development and scalability of three applications that were to be offered on the portal: a personal health record for the Rotterdam Rijnmond region, a closed-circuit video education program, and a publicly accessible information support system for citizens in the region requiring care. The formal task of the first and second author was twofold: to provide timely, intermediate feedback about our findings to project members and other stakeholders, and to assess the pilot phase of each of the applications in three evaluation reports. Our study took 
place between September 2009 and August 2012, and coincides with the period in which ZPR was primarily upheld by public funds. ${ }^{2}$

Throughout this 36-month period, the first author attended three-weekly Project group meetings, bimonthly Steering group meetings, biyearly Board meetings, and several Sounding board groups and subproject activities to collect data for the ZPR study. The second author coordinated and supervised the study, and attended the Project group and Steering group meetings as the Research project leader; like the first author, she was closely involved in the development of the ZPR project. The third author contributed to miscellaneous tasks and issues arising in the project, including the development of pictograms for ZPR's privacy policy; being less involved in ZPR's daily operations - and having more distance to the project - she was able to signal peculiarities in the overall process, and question issues that where easily overlooked from up close. The fourth author was a member of the ZPR Board, representing the University as a consortium partner in the ZPR project. Regular meetings were held between the four authors in which we discussed our ZPR-related research activities and progress.

During our study, the first and second authors' knowledge exchange with project members and other stakeholders took on different forms. Aside from actively participating in the aforementioned formal settings, we attended public ZPR events (such as networking meetings, and the official 'launch' of the portal in September 2011), wrote reports and memoranda with other members of the ZPR project, joined them in various expert meetings, seminars, and trade conferences, and accompanied them on some of their visits to suppliers and other stakeholders. Informally, interactions with project members and other stakeholders took place before and after meetings, either through face-to-face interaction, by telephone, or email correspondence. On numerous occasions the first author joined project members in car rides, lunches, and social activities, alternating small talk with viewpoints on the project.

We drew valuable insights from both formal and informal settings, where the latter allowed us to better understand the political intricacies of the project. At the same time, we were consulted by project members and stakeholders, and shared our own researchers' insights and personal views on the project whenever this was possible and appropriate. We acknowledge that the formative character of our fieldwork is deeply intertwined with 'intervening' or 'informing design' (ZuiderentJerak, 2015), and recognize the importance of critical reflexivity in this process (Bjørn \& Boulus, 2011); our role as participatory researchers merits more attention than the brief reflections we are able to present in this paper.

The material for this paper comprises the first authors' field notes for the ZPR study (September 2009 - August 2012); audio recordings from three Project group meetings, one Steering group meeting, and one Brainstorm session (December 2009 - June 2010); and meeting minutes and memoranda from two Steering group meetings (June 2010, January 2011) and one Board meeting (February 2011) in which the metaphors discussed below explicitly occurred or were implicitly alluded to. While the metaphors did not literally recur in the Steering group and Board meetings, we refer to memoranda and meeting minutes from those groups to illustrate how the metaphors contributed in shaping the course of the project. Relevant excerpts from the aforementioned five audio recordings (up to 25 minutes in length) were transcribed verbatim and coded inductively by the first author.

To understand the role of the blooming flowers and multiple socket metaphors in the ZPR project, we took notice of them as much as possible and reflected on them along the way; this allowed us to retrospectively explore how they were enacted. The two metaphors were part of a management culture in the ZPR project in which the use of analogies, allegories, and idiomatic expressions was profuse. Large and potentially disorderly gatherings, for instance, were referred to as 'Polish Diets' (Poolse landdagen in Dutch), which are proverbially linked to a disorderly meeting of the Polish parliament in the sixteenth century; product pitches for vendors went by the English term 'beauty contest', which - aside from being a synonym of 'beauty pageant' - is informally used to denote any contest decided by popular vote; easily obtained gains were referred to as 'low- 
hanging fruit' (laaghangend fruit); and a portal or application featuring too many functionalities was likened to a 'Christmas tree' (Kerstboom).

In the following section we describe the construing role of the blooming flowers and multiple socket metaphors in the initial phase of the ZPR project. We show how (and by whom) these metaphors were enacted, as well as the consequences of their enactments within the project. We highlight their role in exploring its organizational, technical, and economic boundaries, and in endorsing the portal as an independent, non-partisan attribute in a newly envisioned technical, economical, and social infrastructure for the region. From our analysis we discerned that narratives about 'exploring innovation' and 'exploring new market opportunities' ran parallel with narratives about how to position the ZPR project 'in the market' (i.e., how to 'endorse' it as a competitive contender in the Dutch e-Health landscape). This led us to the distinction between 'exploration' and 'endorsement', each consisting of specific enactments of the two metaphors. Although the concepts of 'exploration' and 'endorsement' can be linked to more or less specific imaginaries - which will be explicated below - our distinction between them is not meant to suggest that one type of enactment preceded the other, or that they occurred independently: they are discursively interwoven, and can be linked to a wide variety of practices.

\section{Flowers Blooming in a Multiple Socket}

Before we focus on how the metaphors were enacted by different people in the project, we need to recount how they first emerged. This brings us to the first official ZPR Project group meeting in December 2009, shortly before the Christmas holidays. By that time, several meetings about ZPR subprojects had already taken place, as well as the first meeting of the Steering group. The Project group meeting started with the program manager enunciating four agenda topics while listing them on a display board: "Report from Steering group - Project progress - Project plans/Flowers on the side - Financial report". As the last agenda topic appeared on the board, the project leader in charge of 'Infrastructure' asked to clarify the meaning of 'flowers on the side'. The program manager replied that they were "the little flowers blooming in the margins of the project plan, beyond the limits of our raked path".

The notion of 'blooming flowers' is frequently used in the context of business and innovation. It is etymologically rooted in the Hundred Flowers Campaign, which was introduced by the Chinese government in 1956 and was presented as an initiative that would promote the cultivation of new ideas, and grant greater freedom of thought and speech to Chinese artists and scientists. Its specific recurrence in narratives on innovation is explained as follows by Kanter:

\footnotetext{
"'Let a thousand flowers bloom'. This slogan, designed to awaken an entire nation to new ideas, offers an apt metaphor for innovation. Innovations, like flowers, start from tiny seeds and have to be nurtured carefully until they blossom; then their essence has to be carried elsewhere for the flowers to spread." (Kanter, 1988: 170)
}

In the ZPR Project group, the blooming flowers metaphor came to denote e-Health projects in the Netherlands that were deemed appropriate or interesting enough to be 'offered through' or 'integrated in' the portal. Projects emerging 'in the margins of the project plan' thus became known as bloemetjes awaiting to blossom; in this paper we opt for the translation 'blooming flowers', which in our view best conveys the program manager's description.

The added metaphorical rendition of ZPR's 'raked path', which was not clarified by the program manager, must be understood in relation to ZPR's five subprojects existing at that time (one pertaining to the technical infrastructure, one for each of the three applications to be 'integrated' in the portal, and one research component) as well as to one of the espoused objectives in the ZPR project: to stimulate the development of new e-Health initiatives and activities in the region (ZPR, 2009). The blooming flowers metaphor thus conveyed ZPR's envisioned role as a platform for e-Health innovation, and the necessity and willingness to accommodate potentially useful developments beyond the lineaments of ZPR's project structure - e.g., the neat, orderly, and more or 
less clearly predefined itinerary suggested by the 'raked path'.

The notion of 'integrating' (or 'latching on') e-Health applications in the ZPR portal was conveyed through the view of the portal as a multiple socket. ${ }^{4}$ This term first occurred during the same Project group meeting in December, when the program manager informed the group about a past meeting with project leaders of another health portal project in the Netherlands:

"Actually they [the project leaders of the other portal project] choose a very different concept; while we are pretty much looking for new software, their plan is really just to become something like a multiple socket [stekkerdoos], where everything that works and is properly developed can be plugged into. So for us it's very important to keep an eye on that, which plugs they will be plugging into their own sockets in the next months, and to plug those in as well. [...] We've chosen a slightly different concept, where we say: we have to deliver those things as well in order to generate traffic." [program manager, December 15, 2009]

In its first occurrence, the term stekkerdoos did not raise questions among the project members. It reappeared verbatim on the agenda of a brainstorming meeting after the Christmas holidays. Several ZPR project leaders, the financial controller, and the director of the Regional Health Information Organization (RHIO) were present. As they discussed the potential benefits for other companies to 'plug into' ZPR, the program manager expressed her preoccupations on how to make this work:

"I still have one concern, which is that on a very short term we will need to wheel in money, ${ }^{5}$ because I believe that the portal should be made more suitable to also serve as a multiple socket." [program manager, January 7, 2010]

In reaction to this, the Infrastructure project leader asked the program manager asked the program manager to clarify his understanding of the term 'multiple socket' in the project's context:
"So in fact, a multiple socket is something that you offer to someone who has a ready-made application \{yes! - program manager $\}^{6}$ with users, administration, on which everything works?" [project leader Infrastructure, January 7, 2010]

The program manager acknowledged this explanation, adding that the integration between applications and the portal could take on different forms in different cases, and that it would require negotiations with entrepreneurs:

\footnotetext{
"Yes what you have is... yeah actually it depends, we'll have to talk about it with the entrepreneurs. PatientCom, for example, has a sort of application for diaries, so people can keep their own diary, for diabetes and for ehm... well, they really want to keep data storage to themselves." [program manager, January 7, 2010]
}

This quote illustrates the program manager's awareness of the ambiguity of the multiple socket metaphor: the variation and negotiation she alludes to stand in contrast with the uniformity and rigidity of a multiple socket. Despite this ambiguity, the view of the portal as a multiple socket soon gained currency within the Project group. During our meetings at the University, which ran parallel to the ZPR project, we reflected on the meaning and use of the blooming flowers and multiple socket metaphors. Our first reflections on these metaphors date back to January 20, 2010, when we tentatively construed the multiple socket as a model of integration and as a metaphor for the ambition to 'standardize everything'. Rather than firmly hanging on to these ideas, we tried to keep an open view on how the use of this metaphor would develop; framing it as a 'model of integration', however, was an analytical choice that persisted, and that colored our subsequent observations and interpretations. In what follows we describe two ways in which the blooming flowers and multiple socket metaphors were enacted, with the purpose to gain a better understanding of the relation between metaphors and practices in the ZPR project. We present these enactments in separate sections, each following a chronological order. 


\section{Exploration}

The blooming flowers metaphor was deeply intertwined with the search for new e-Health applications and market opportunities in the ZPR project. These explorative activities primarily involved Project group members, and were at their height between February and August 2010. The importance of investigating 'interesting developments' for the multiple socket was addressed as follows by the program manager, while planning the attendance of an upcoming ICT fair:

"My thought is: let's go all together, so we can compare notes: what did you see, what did you notice, what can we do with this? I assume that we'll see a number of interesting developments for the multiple socket." [program manager, February $2,2010]$

The program manager sought a systematic solution to maintain a structured overview of what could be 'plugged into' the portal. An overview of this kind was meant to keep Project group members updated on current findings, while providing a means of comparing different applications as well:

"[...] the question is: do we create a single document, and make an entry for each one, and look at the entire list together once or twice a month and say: these are candidates for the multiple socket? And will we say: we can invite so-and-so for an interview? [...] we need a central point where things are directed to, someone who rubricates them or stores them somewhere so we can come together and say: this looks interesting, if it works well, can we latch it on to the portal? Does it have added value for the portal, or is there something underneath that is useful to us?" [program manager, February 2, 2010]

The program manager thus envisioned a standardized format for keeping track of the blooming flowers; this would enable a more or less structured exploration of products, activities, and services beyond the aforementioned confines of ZPR's project delineation. In her role as Research project leader, the second author was asked to create a template for a working document, which she divided into twelve descriptive categories: 'education', 'prevention and lifestyle', 'self-management', 'support groups', 'e-mental health', 'search and find', 'medication', 'e-learning', 'home automation', 'telemedicine', 'record keeping', and 'internet appointments'. These categories helped to discern different types of e-Health applications based on a standard set of principles; in accordance with this template, each blooming flower was described separately and classified by 'type of ICT tool' (with descriptors loosely based on the aforementioned categorization), 'sector' (such as 'prevention', 'cure', 'care', etc.) and 'target audience' (such as 'patients', 'health providers', 'children', 'physiotherapists'). Descriptions varied in length from a few sentences to several paragraphs, and were accompanied by the URL associated with the application or project.

While the Research project leader worked on the template, the Infrastructure project leader set out to explore the technical requirements for a 'good' multiple socket. Having questioned the multiple socket metaphor in the previous meeting, and having recently visited the software vendor who was contracted to build ZPR's technical platform, he reported back to the Project meeting by explaining that the 'universal' character of multiple sockets did not apply to the ZPR case, nor to other portals: "You cannot build one multiple socket for all, it doesn't work like that in software land" (February 12, 2010). Noting that it was fundamental to know in advance what requirements ZPR had to meet in order to deliver a technical architecture for ZPR ("the question is: how do you wish to make it available? And not: how do you plug into it") he added that making different applications 'interoperable' with each other on a single portal would not be a feasible goal.

Interpreted as a literal analogy, the multiple socket metaphor thus revealed its technical and organizational shortcomings: different e-Health applications are based on different 'installed bases' (Hanseth \& Ciborra, 2007) which are in turn relegated to different standards and infrastructures. Despite this shortcoming, the multiple socket metaphor temporarily configured the relation between applications and the portal as a problem of fit, both in a technical sense (finding a 'fit' between plug and socket) and economically 
(seeking 'compatible' business models to'plug into' the portal). However, as Project group members continued to discuss the integration of third party applications as an act of 'plugging into' the portal, the metaphor did not help to make the politics of technology and infrastructural work visible. 'Infrastructure' remained a technical challenge, and the main person responsible for its development was the Infrastructure project leader. We will further elaborate on this in the Endorsement section.

Bringing back our attention to the blooming flowers, the working document contained formalized descriptions of 41 e-Health applications by the end of February of 2010. Examples included a module for scheduling appointments with health providers, an educational course for adolescents with symptoms of depression, and a Wi-Fi-enabled audio messaging device for young children in hospitals. Typically, these 'blooming flowers' were found in online media publications and printed press, through networking gatherings, or by word of mouth. Information and insights about these applications were shared with Project group members during the three-weekly meetings, and sometimes by e-mail.

Aside from providing project members with a tangible, selected overview of third party e-Health applications in the Netherlands, the blooming flowers metaphor brought about a classification of innovation that enabled side-by-side comparisons between different initiatives. At the end of February, six Project group members were asked to evaluate the blooming flowers and to rank them; the assessment was based on two generic criteria ('who benefits?' and 'relevance to ZPR goals?') divided in several items, ${ }^{7}$ and featured a rating scale from 1 to 10 . The form to be filled out for each application became known as the 'blooming flowers form' (bloemetjesformulier), and was referred to as such in subsequent Project group meetings.

In the following five months, discussions about the blooming flowers revealed how the exploration work was gradually transforming into decision work, and that the latter was a long process. In the April Project group meeting, a debate arose on how to move from the current working document to the integration of ten applications on the portal by the end of 2010, as was formulated in ZPR's year plan. In her role as Research project leader, the second author pointed out that the working document could help to decide which applications to select for the portal:

\footnotetext{
"You can use that document I made to find out what kind of applications there are... you know, some applications have more of a diary functionality, which you can edit yourself, some are more about communication between health care providers and patients, there are applications focused on giving a specific type of information, which can be text-based or visual... and that's a type of ordering that could be helpful. [...] It would be nice if there were some sort of balance, if we could offer at least one of each of those types of information on the site" [project leader Research, April 27, 2010]
}

This suggestion not only serves to illustrate the formative interventions that we made to the project as researchers - seeing the working document as an instrument to create order - but it shows how the exploration process was built up: from assessing and classifying innovations to seeking a certain 'balance' in them. A congruent strategy was proposed by ZPR's financial controller, who suggested making a selection of applications based on what could be 'coupled' to the portal relatively easily, without too much effort or high costs:

\footnotetext{
"Perhaps you should sort out what can be achieved easily, and make something like a global estimate of the time required to couple something like that [a blooming flower] to Zorgportaal, and to make a selection on that basis" [financial controller, April $24,2010]$
}

This hinted at the idea that some applications or initiatives would require more effort than others. More precisely, the financial controller felt that the focus should be diverted from what she termed 'experiments'. From this emerges a distinction between established, successful, up-and-running applications and comparatively obscure initiatives by hospital doctors that were still going through trial stages:

"Some of those flowers are, with all due respect, just experiments by people who are not fully 
dedicated to creating this type of applications, like health care providers" [financial controller, April 24, 2010]

This qualification of some applications or initiatives as 'experiments' adds a new dimension to the view of the "little flowers blooming in the margins of the project plan, beyond the limits of our raked path". Evidently, the blooming flowers now required a 'raked path' of their own in order to be prioritized: simply 'blooming in the margins' was not enough. But the differentiation between 'just experiments' and other initiatives was highly normative: drawing the line between 'experimental' and accomplished applications or initiatives (meaning 'suitable' and 'unsuitable' in this context) was a matter of contention, and the issue of how to draw that line was never settled in the Project group. In response to the financial controller, the program manager contested that any of the blooming flowers in the overview were 'experimental'; she stressed that most of them were actually well-funded, award-winning initiatives. This contestation of the label 'experiment' points to the problematic definition of the term itself (who decides what qualifies as an experiment, and on what basis?), as well as to a devaluation of the notion of 'experimentality': the blooming flowers were not 'just experiments'. The program manager expressed her concern that ZPR would remain an empty portal if they would continue to add new blooming flowers to the overview, and that the focus should be shifted towards ZPR's content. She proposed to create a shortlist containing six or seven blooming flowers that 'already work well' to be made available through the ZPR portal before November 2010:

\section{"The fastest way of creating a lot of content on [the portal], or interesting activities, is to think about the things that already work well. Meaning flowers that we have already found." [program manager, April 24, 2010]}

By mid May the working document contained 57 blooming flowers. The Project group convened again, and the discussion on how to make an appropriate selection continued: who would decide on what to select, and what would be the role of the Steering group in this process? Having discussed the matter beforehand, the Research project leader and the program manager proposed to write a memorandum for the Steering group:

"Those 57 items could all be placed under'nice health links' [...] but in the end it's about making a distinction: what will you be offering through ZPR?" [project leader Research, May 18, 2010]

"Our proposal is to make some sort of exploration, to write a small plan, and to hand that over to the Steering group. To say to the Steering group: this is what we wish to develop. With these entrepreneurs or these providers we want to talk about a real collaboration, and to connect things to the portal in the right look and feel, which means that we will have to pay for that part of the look and feel for them; and yes, that requires money, can that be paid from the portal or...?" [program manager, May $18,2010]$

The criteria for this new selection procedure were elaborated in a memorandum entitled 'Acceleration of Zorgportaal development' (ZPR, 2010), which featured on the agenda of the Steering group meeting in June. In the memorandum the program manager expressed her opinion that the development of ZPR was not proceeding fast enough, as efforts were primarily directed at the technical infrastructure of the portal and the three applications that were developed in association with ZPR. Without resorting to the blooming flowers metaphor she wrote: "I believe it is important that we put more energy in collaborations with strong private partners with good services for both care providers and citizens/patients." The memorandum presented three criteria based on which the blooming flowers could be distinguished: 'hyperlinks to other sites', 'services for which the visual presentation of the application is integrated with Zorgportaal', and 'services for which the application is integrated in Zorportaal'. This was followed by an overview of the aforementioned twelve categories from the blooming flowers template, and two formal requests to the Steering group: "Agreeing with an accelerated development of content on Zorgportaal Rijnmond, so that it can be presented for decision at the Board meeting; Determining together who 
decides what services will be offered on Zorgportaal" (ZPR, 2010).

In the June 2010 Steering group meeting, where the blooming flowers metaphor was incidentally used by one of the Steering group members in relation to the digitalization of health care ("You see that there are many flowers blooming there"), the memorandum led to a discussion about envisioned partnerships with private parties. Asked to clarify her view on this matter, the program manager replied:

"I think we need to look at it [...] per individual case: what are the costs, what are the returns, what is the short term business case, the long term business case. [...] It will vary for each... blooming flower, I think. For each... new activity. What are the costs of latching on, and how do you wish to latch on, right? Do you want to be a link from here, or do you really want to be incorporated in the portal... you can imagine that if you really want to be incorporated in the portal, that the costs will be higher" [program manager, June 14, 2010]

The Steering group agreed to give a positive advice to the Board regarding the 'accelerated development of content', which entailed the allocation of a larger share of the program manager's hours to exploring the financial implications of partnerships with private parties. Anticipating future endorsement activities, one of the management delegates summarized the discussion as follows: "How do you market it? Basically it's all a matter of marketing for Zorgportaal". Between June 2010 and January 2011 the term 'business case' gained prominence on the agenda of the Project group and Steering group. Third party applications were regarded as important for the financial sustainability of ZPR, but the project manager did not expect things to go smoothly. In an interview with the first author she expressed her concerns as follows:

"Look, we obviously face a heck of a problem in about two... one year from now. One year from now [the portal] must be so solid that we can pay for the infrastructure! Thanks to the applications on it, and the underlying business cases, if enough traffic is coming in... well, it's all still very exciting! Really exciting! I have no idea! I have yet to see any application in the Netherlands that can support itself based on citizens willing to pay for it. [...] There is an underlying assumption that people are going to use applications, and that there's a business model behind each application, but uh... a lot of the revenue that goes to one [entrepreneur] depends on the investments made by others" [program manager, July 8, 2010]

Six months later, on January 10, 2011, a special meeting was held in which five suppliers 'pitched' their products or services to the Steering group. Two ZPR project leaders, two project leaders from the largest teaching hospital in the region, and the first author were also invited. Among the presented products were the online diary application for patients with chronic diseases by PatientCom, which allegedly had tens of thousands of users in the Netherlands at that time, and an application for online satisfaction surveys by ResearchCom. All people attending were asked to make notes, and to reflect on the potential of each proposition. In an interview with the first author (January 17, 2011), the RHIO director explained his preference for PatientCom by pointing out the "clear business case in their presentation", and expressed his dislike of ResearchCom for "not having a clear business: how will we pay for it?" Similarly, the minutes of the following Steering Group (ZPR, 2011a) emphasized the 'business case' of both applications, briefly describing the presentations as follows: "The self-help diaries by PatientCom have been well received. The presentation was very illustrative. It is directly clear for a patient how to use the diaries. Moreover, PatientCom has a clear business case. For the application by ResearchCom we need more clarity about the business case on the longer term."

This reconstruction shows how the exploration of blooming flowers gained a more economic character as ZPR's own 'business case' and financial sustainability became a more pressing issue; we will elaborate on the marketing-oriented enactment of this metaphor (framing the ZPR portal as a business opportunity) in the Endorsement section. The blooming flowers metaphor contributed in shaping the selection procedure of applications for the ZPR project by articulating the functional and financial dimensions of prospective e-Health innovations. It led to the creation of a standardized form that gave Project group 


\section{Table 1. Exploration}

\begin{tabular}{|c|c|c|c|c|}
\hline Imaginary & Metaphor & How it was enacted... & ... and by whom & What it led to \\
\hline \multirow{4}{*}{$\begin{array}{l}\text { Portal as a } \\
\text { platform for } \\
\text { e-Health } \\
\text { innovation }\end{array}$} & \multirow[t]{2}{*}{ Blooming Flowers } & $\begin{array}{l}\text { Searching for new } \\
\text { applications \& market } \\
\text { opportunities }\end{array}$ & $\begin{array}{l}\text { Project group } \\
\text { members }\end{array}$ & $\begin{array}{l}\text { The search led to a selected } \\
\text { inventory/overview of e-Health } \\
\text { projects in the Netherlands }\end{array}$ \\
\hline & & $\begin{array}{l}\text { Classifying innovation } \\
\text { using a standardized } \\
\text { working document }\end{array}$ & $\begin{array}{l}\text { Project group } \\
\text { members }\end{array}$ & $\begin{array}{l}\text { The working document evolved } \\
\text { into a form that contributed } \\
\text { to/informed the inclusion and } \\
\text { exclusion of potentially useful } \\
\text { applications }\end{array}$ \\
\hline & \multirow[t]{2}{*}{ Multiple Socket } & $\begin{array}{l}\text { Investigating ways to } \\
\text { build the portal }\end{array}$ & $\begin{array}{l}\text { Project leader } \\
\text { 'Infrastructure' }\end{array}$ & $\begin{array}{l}\text { Task of translating the metaphor } \\
\text { into technical requirements/ } \\
\text { specifications }\end{array}$ \\
\hline & & $\begin{array}{l}\text { Searching for new } \\
\text { applications to plug into } \\
\text { the portal }\end{array}$ & $\begin{array}{l}\text { Project group } \\
\text { members }\end{array}$ & $\begin{array}{l}\text { The derivative 'plug into' } \\
\text { metaphor configured the relation } \\
\text { between application and portal } \\
\text { as a problem of alignment, both } \\
\text { technically and economically }\end{array}$ \\
\hline
\end{tabular}

members insight in user-payer arrangements, access procedures and types of data management and maintenance for different types of applications. Similarly, the multiple socket metaphor enforced the imaginary of a platform for e-Health innovation in which those applications could be 'plugged into'. Table 1 illustrates the different ways in which the metaphors were enacted in light of the view of the portal as a platform for e-Health innovation.

\section{Endorsement}

Aside from being viewed as a platform for innovation, the ZPR portal was also heralded as 'the' future gateway for health care providers and recipients in the Rotterdam Rijnmond region (cf. ZPR, 2009). Using the blooming flowers metaphor in reference to e-Health developments elsewhere in the Netherlands, the program manager presented her view of ZPR as an inclusive, open, and outwardly oriented project. Project group members and other stakeholders invested substantial effort in mobilizing potential participants in the ZPR project; among those stakeholders was the chief medical information officer (CMIO) of the aforementioned teaching hospital. An avid proponent of the Continuity of Care Record (CCR) standard, the CMIO frequently spoke at medical IT-gatherings, where he championed ZPR as a platform for standardized health information exchange (HIE). His views on how to unify language and semantics in HIE expressed similar narratives of inclusiveness and outward orientation.
He deemed cooperation with third parties as crucial, and focused on getting regional hospitals 'on board' of the ZPR project. Meanwhile, networking sessions and expert meetings were organized to talk with entrepreneurs about how ZPR could contribute in achieving their goals; the prospect of creating new business activities 'around' ZPR - or making 'flowers bloom' - required sensibilities toward a complex of technical, organizational, economical, and legal challenges. In reaching out to care providers in the region, ZPR was promoted as a not-for-profit gateway for e-Health: through its novel technical infrastructure it would facilitate online services, as well as improve communication between different parties in the region.

Within the confines of the Project group, the multiple socket metaphor was enacted as a means to discriminate 'good' from 'bad' e-Health applications and services. In a landscape cluttered with e-Health initiatives, it was important to be critical about offers or propositions by third parties:

"I think we should be in control [of whom to approach], and think of what company suits us best. So that we only attract the cream of the crop, to which we offer that multiple socket function.

And not just any idiot with an idea." [program manager, February 10, 2010]

To the 'outside world', however, the metaphor became instrumental in communicating a sense of unity, suggesting neutral ground, development potential, and a low threshold for participation. The image of the multiple socket meant to 
convey the notion of a broad platform serving the needs of different groups, and posing no threats or risks to prospective participants. It echoed the promise of a technically accessible and politically 'transparent' infrastructure. Its political 'impartiality' was explicated as follows in a discussion on February 10, 2010 between the program manager, the $\mathrm{RHIO}$ director, and the CMIO of the teaching hospital about facilitating or generating new business activities:

Program manager: "You say that those applications all belong to Zorgportaal. But you can also place those applications elsewhere; we will just be a multiple socket."

RHIO director: "No but that's exactly what I mean. [...] The business that we develop, it's intended to make Zorgportaal a non-threatening component that you can purchase as your infrastructure; that you don't have the feeling that you need to provide one of your own if you want to do any business at all. [...] You have to make sure that you're the party of which I say: that's where I'll place it, and there's no risk for me to lose control over my product"

CMIO: "and that it delivers, it delivers contact between all healthcare providers in the region yyes - RHIO director\}, it delivers contact with patients \{standards! - RHIO director\}, it delivers standards \{and the multiple socket - RHIO director\} yes, but in a secure manner."

The CMIO, who was a member of the Steering group, never 'bought into' the metaphor as such. Among Project group members, however, the representation of ZPR as a multiple socket in which third parties 'plug in' their applications formed a dominant narrative in the early development stage. Although there was still little clarity on the technical and organizational requirements for this model of integration (or on its political and legal implications), the multiple socket complemented the blooming flowers metaphor in endorsing ZPR's envisioned role as an independent and non-partisan attribute in a newly envisioned infrastructure for the region. Like the blooming flowers metaphor, it prioritized a technical and economical framing of ZPR (a 'component that you can purchase') over concerns about its relation to health care practices, organizations, and citizens in the Rotterdam Rijnmond region.

After February 12, 2010, when the Infrastructure project leader openly disqualified the view of the portal as a multiple socket, this metaphor fell into disuse. Despite its inadequacy as a representation of the 'integration problem' that Project group members were attempting to define, the multiple socket metaphor persisted in derivative expressions such as 'plugging into the portal'. Such expressions continued to recur among project members in discussions about the endorsement of $Z P R$, where the latter featured as a 'neutral' platform or base where different applications could be plugged into or 'latched on to'; this idea was typically visualized in early architecture documents as a series of cylindrical structures positioned on a horizontally placed rectangle, much like pillars on a construction site.

Table 2 illustrates how the metaphors were enacted in relation to the view of the portal as 'the' gateway for e-Health in the Rotterdam Rijnmond region. Our descriptions show how different enactments of the blooming flowers and multiple socket metaphors prioritized a technical and economical framing of $Z P R$, while concealing the

Table 2. Endorsement

\begin{tabular}{|c|c|c|c|c|}
\hline Imaginary & Metaphor & How it was enacted... & ... and by whom & What it led to \\
\hline \multirow[t]{3}{*}{$\begin{array}{l}\text { Portal as 'the' } \\
\text { main gateway for } \\
\text { e-Health in the } \\
\text { region }\end{array}$} & \multirow[t]{2}{*}{ Blooming Flowers } & $\begin{array}{l}\text { Constructing the project } \\
\text { as inclusive, open, } \\
\text { welcoming, outwardly } \\
\text { oriented }\end{array}$ & $\begin{array}{l}\text { Program } \\
\text { manager; } \\
\text { CMIO }\end{array}$ & \multirow{3}{*}{$\begin{array}{l}\text { Mobilization of prospective } \\
\text { participants and consortium } \\
\text { partners; product pitch for } \\
\text { e-Health vendors }\end{array}$} \\
\hline & & $\begin{array}{l}\text { Marketing the ZPR portal } \\
\text { as a business opportunity }\end{array}$ & $\begin{array}{l}\text { Program manager } \\
\text { and } \\
\text { Steering group } \\
\text { members }\end{array}$ & \\
\hline & Multiple Socket & $\begin{array}{l}\text { Constructing the portal } \\
\text { as neutral, impartial, and } \\
\text { non-threatening }\end{array}$ & RHIO director & \\
\hline
\end{tabular}


politics of technology and infrastructural work. This generativity of metaphors requires further reflection; in the following section we discuss what roles the metaphors played in our study, and how the analysis of discursive attributes can contribute to the study and development of Ils.

\section{Discussion and Conclusive Remarks}

Metaphors are not 'innocent' or neutral descriptors of abstract concepts. In our empirical description we presented them as operationalizations of sociotechnical imaginaries pertaining to 'integrated' and 'personalized' health care. As representations of an imagined social and technical order, metaphors can indeed be misguiding conveyors of infrastructural work. Our reconstruction of the emergence of the multiple socket metaphor shows how the program manager foresaw that the integration between applications and the portal would take on different shapes in different cases. The allegorical 'fit' between plugs and sockets, which suggest a view of closed and stabilized artefacts and standards (Bijker et al., 2012: 37), fell short in representing infrastructural work in a decentralized, highly heterogeneous network of interdependent actors.

As a heuristic device, the multiple socket metaphor prompted project group members to 'spell out' its meaning (Schön, 1996: 138) by reflecting on the underlying assumptions in the context of infrastructural work. Misguiding or not, the metaphor temporarily acted as a "powerful means of organizing work and intellectual practice" (Bowker \& Star, 2000: 314) by simplifying abstractions, making them manageable, and supporting their circulation (Czarniawska-Joerges \& Joerges, 1992, 1996). Viewed from this organizational perspective, Ellingsen \& Monteiro (2008) have argued that the added value of metaphors to project work resides in their ambiguous and versatile character: if they work well, it is exactly because they are not precise representations of reality.

More importantly, our description of the two metaphors' enactments shows how they configured innovation as a definite, cognizable, and classifiable commodity. As such they were 'generative' metaphors, actively contributing to the way in which Project group members framed problems of exploration and endorsement in the development of the portal. The multiple socket metaphor pre-empted the contours of ZPR as something where things could be 'plugged into', despite the facetious representation of flowers blooming in a multiple socket. Both the multiple socket and the contiguous plug-in metaphor reduced the concept of infrastructure to a mere arrangement of objects, or a "thing stripped of use" (Star \& Ruhleder 1996: 113): they prioritized technical preoccupations and solutions over the social and organizational dimensions of infrastructure, temporarily sustained a deterministic view of the infrastructural work at hand, and concealed the relationship between technology, human work, and users in this process. The blooming flowers metaphor helped to configure ZPR's economical infrastructure by structuring the manner in which ZPR's technical and economical relation to markets and innovation were envisioned. Our empirical data show how the problem of selecting third-party applications for the portal was linked to the classifications and rankings produced by the blooming flowers form.

The blooming flowers metaphor travelled beyond the confines of the Project group, but it required translations to circulate. Its playfulness best suited the Project group setting, where members convened most frequently, and where much of the actual development work took shape. In the Steering group, the project manager chose different terms to address the portal and the third party applications; our quote from June 14, 2010 nicely illustrates how she takes back the term 'blooming flower' and speaks of 'new activity' on the portal. Similarly, meeting minutes reported about 'third party applications' and the 'accelerated development of content' (ZPR, 2010; 2011). In an open letter to hospital directors in the region, the ZPR Board simply used the term 'applications/ services' (ZPR, 2012). In order to enroll actors in more formal settings, such as the Steering group and Board meetings, imaginaries of integrated care and innovation perhaps required more conventional terms in order to be taken seriously.

The blooming flowers and multiple socket metaphors helped to change abstract concepts about markets, business cases, and innova- 
tion into comprehensible and non-threatening images. Their playful character may also have helped to sustain a sense of enthusiasm among Project group members, if only temporarily. Although we are unable to illustrate the latter point empirically, we believe that the blooming flowers metaphor conveys a witty and endearing view of innovation, exuding a sense of cheerfulness and detachment from the perceived (and often experienced) seriousness and harshness of the project's technological, economical, and political reality. It helped ZPR project members and other stakeholders to promote the imaginary of an open and inclusive portal project, and then sustained this imaginary by informing the manner in which 'promising' or 'potentially interesting' e-Health applications were viewed, even when the blooming flowers form was no longer used. The metaphor's playfulness disguised the fierceness of economic competition, the pervasiveness of conflicting interests and agendas, and practical difficulties in devising a sustainable business model for the portal. In this sense it contributed to a concealment of the politics of infrastructures (Winner, 1986; Star, 1999). Furthermore, it conveyed a sense of openness and inclusion in the innovation process that masked the normative choices it involves, while obscuring the materiality and politics of infrastructural work (Oudshoorn et al., 2004). As the differentiation between 'experiments' and what we termed as 'accomplished' applications illustrates, drawing the line between them remained an implicit problem. Indeed, most applications or initiatives were being tacitly excluded from the metaphorical "cream of the crop", or not included in the selection that was deemed necessary to 'accelerate' content development on ZPR.

As an attribute of infrastructural work, the multiple socket metaphor temporarily helped to construct the imaginary of a portal that 'provides' or 'facilitates' a unified and user-friendly technical infrastructure (i.e., based on a 'single sign-on' principle) and to express the anticipation of a future of 'integrated' and 'personalized' health care by rendering promises of uniformity, standardization and interoperability through the derivative 'plug in' metaphor. At the same time, its predominantly technological and economical enactment obscured the relationship between technology and human work - an element that has been extensively explored in CSCW literature (Hanseth \& Ljungberg, 2001; Aanestad, 2003; Ellingsen \& Monteiro, 2003, 2006; Winthereik \& Vikkelsø, 2005; Monteiro et al., 2013).

Our analysis suggests that metaphors help to make project imaginaries definite, cognizable, and classifiable, and that in doing so, they can conceal the politics of infrastructural work. More than merely acting as heuristic devices in the development of Ils, we agree with Monteiro and Hepsø that they "act as forceful 'actors' that contribute substantially to the shaping of the technology [...] as a powerful ally" (Monteiro \& Hepsø, 2002: 146). Their coerciveness increases as they become more deeply engrained in the project's imaginary; having described their enactments as elements of sociotechnical imaginaries, we have shown how they contributed to the prescription of futures and agendas for ZPR, while at the same time drawing away the attention from the human work required in developing and maintaining infrastructures, and from questions about the relation between infrastructures and their users.

The implications of these observations reach much further than we were able to illustrate in this paper. Most importantly, we wish to signal that studying the use of linguistic attributes in Ils - and of metaphors and metaphorical expressions in particular - can lead to the insight that "it could be otherwise" (Woolgar \& Nyland, 2013: 7). The act of 'spelling out' metaphors (Schön, 1996) can be likened to the 'unpacking' of technologies or interventions (Zuiderent-Jerak \& Jensen, 2007), in that it reveals what is hidden or obscured, and therewith opens up a space for new imaginaries and alternative strategies. In the context of e-Health integration, alternative ways of framing the problems at stake may be crucial to overcome governance challenges or dilemmas (e.g., regarding the ownership of data, data distribution, surveillance, privacy, etc.). Inquiries into the reconstruction of underlying conflicting frames can help to devise such alternatives (Schön, 1996: 139), possibly leading to re-conceptualizations of 'infrastructure' and 'integration'.

By focusing on the generativity of metaphors in the development of the ZPR portal, we showed 
how they contributed in framing the problems at hand in a cognizable yet ambiguous manner. By diverting the gaze from sociotechnical and political complexities, metaphors have the potential to transform contested, disconcerting, or unsettling ideas into seemingly innocuous (or indeed favorable) images; as such, they actively contribute to the manner in which problems are defined, and how people and organizations are called into action. The potentially far-reaching consequences of metaphors as constitutive elements of infrastructures - elements that help to construe their ontological status and their imagined social order, and that are perpetuated and shaped by that order at the same time - deserve more critical scrutiny in research on Ils, as well as in the everyday work practices of project managers, developers, and policy makers. Engaged participatory research can contribute to redirect the gaze on those sociotechnical and political complexities, and to raise timely questions about the implications of imaginaries that bypass the materiality and politics of infrastructure; in that process, the act of 'spelling out' metaphors can open up spaces for alternative strategies in lls. The use of metaphors and metaphorical expressions is indeed so widespread in e-Health (and in the field of information and communication technologies in general) that it easily escapes to the attention of people who live with them on a daily basis. Although scholars from different disciplinary backgrounds have long embraced the intertwinement of discourses and practices in their work, continuous research efforts are required to better understand the agency of discursive attributes in infrastructural projects. While the focus on seemingly insignificant or trivial attributes of social life is altogether a well-established practice in STS, we hope to have shown why the inclusion of discursive attributes in the STS repertoire is appropriate and recommendable.

\section{Acknowledgements}

This study was conducted on a PhD grant from the Erasmus University Rotterdam. The grant was allocated for the evaluation of the Zorgportaal Rijnmond portal. The portal was subsidized by the Municipality of Rotterdam, the Dutch Ministry of Economic Affairs, and consortium partners through the 'Pieken in de Delta' program. The authors thank the respondents for sharing their knowledge about the project, as well as Bethany Hipple Walters, the journal reviewers, and the editor for their valuable comments and feedback. 


\section{References}

Aanestad M (2003) The Camera as an Actor Design-in-Use of Telemedicine Infrastructure in Surgery. Computer Supported Cooperative Work 12(1): 1-20.

Aanestad M \& Jensen CB (2011) Building Nation-Wide Information Infrastructures in Healthcare Through Modular Implementation Strategies. The Journal of Strategic Information Systems 20(2): 161-176.

Andersen PB \& Madsen KH (1988) Design and Professional Languages. In: Andersen PB \& Bratteteig T (eds), Computer and Language at Work. Oslo, Norway: Department of Informatics, 157-196.

Baird A \& Nowak S (2014) Why primary care practice should become digital health information hubs for their patients. BMC Family Practice 15: 190.

Bal R \& Mastboom F (2007) Engaging with Technologies in Practice: Travelling the Northwest Passage. Science as Culture 16(3): 253-266.

Bansler J \& Kensing F (2010) Information Infrastructures for Health Care: Connecting Practices Across Institutional and Professional Boundaries. Computer Supported Cooperative Work 19(6): 519-520.

Bijker WE, Bal R \& Hendriks R (2009) The Paradox of Scientific Authority: The Role of Scientific Advice in Democracies. Cambridge/London: The MIT Press.

Bijker WE, Hughes TP \& Pinch T (eds) (2012) The Social Construction of Technological Systems: New Directions in the Sociology and History of Technology. Cambridge/London: The MIT Press.

Bishop A \& Star SL (1996) Social informatics of digital library use and infrastructure. Annual Review of Information Science and Technology 31: 301-403.

Bjørn P \& Boulus N (2011) Dissenting in reflective conversations: Critical components of doing action research. Action Research 9(3): 282-302.

Bjørn P \& Kensing F (2013) Special Issue on Information Infrastructures for Healthcare: The Global and Local Relation. International Journal of Medical Informatics 82: 281-282.

Bowker GC \& Star SL (2000) Sorting Things Out: Classification and its Consequences. Cambridge/London: The MIT Press.

Bowker GC, Baker K, Millerand F \& Ribes D (2010) Toward Information Infrastructure Studies: Ways of Knowing in a Networked Environment. In: Hunsinger J, Klastrup L \& Allen M (eds) International Handbook of Internet Research. Amsterdam: Springer Netherlands, 97-117.

Carroll J \& Thomas J (1982) Metaphors and the Cognitive Representation of Computing Systems. IEEE Transactions on Systems, Man, and Cybernetics 12(2): 107-116.

Carroll J \& Mack R (1985) Metaphors, computing systems, and active learning. International Journal of ManMachine Studies 22(1): 39-57.

Carroll J, Mack R \& Kellogg W (1988) Interface Metaphors and User Interface Design. In: Helander W (ed) Handbook of Human Computer Interaction. Amsterdam: Elsevier Science Publishers, 67-85.

Constantinides P (2013) The communicative constitution of IT innovation. Information and Organization 23: 215-232.

Czarniawska-Joerges B \& Joerges B (1992) Linguistic Artifacts at Service of Organizational Control. In: Gagliardi P (ed) Symbols and Artifacts: Views of the Corporate Landscape. Berlin: De Gruyter, 339-364.

Czarniawska-Joerges B \& Joerges B (1996) Travels of ideas. In Czarniawska-Joerges B \& Sevón G (eds) Translating organizational change. Berlin: De Gruyter, 13-47.

De Mul M, Adams S, Aspria M, Otte-Trojel T \& Bal R (2013). Hart voor de regio: Patiëntenportalen en regionale ontwikkelingen in Nederland. Erasmus University Rotterdam \& ZonMw. September 2013. Report in Dutch. Available at: http://www.bmg.eur.nl/fileadmin/ASSETS/bmg/Onderzoek/Onderzoeksrapporten Working_Papers/2013/Onderzoeksrapport_2013.13.pdf (accessed: 8.10.2015). 
Detmer D, Bloomrosen M, Raymond B \& Tang P (2008) Integrated Personal Health Records: Transformative Tools for Consumer-Centric Care. BMC Medical Informatics and Decision Making 8(45): e1-e14.

Ellingsen G \& Monteiro E (2003) A Patchwork Planet: Integration and Cooperation in Hospitals. Computer Supported Cooperative Work 12(1): 71-95.

Ellingsen G \& Monteiro E (2006) Seamless Integration: Standardization Across Multiple Settings. Computer Supported Cooperative Work 15(5-6): 443-466.

Ellingsen G \& Monteiro E (2008) The organizing vision of integrated health information systems. Health Informatics Journal, 14(3): 223-236.

Ellingsen G \& Røed K (2010) The Role of Integration in Health-Based Information Infrastructures. Computer Supported Cooperative Work 19(6): 557-584.

Ellingsen G, Monteiro E \& Røed K (2013) Integration as an Interdependent Workaround. International Journal of Medical Informatics 82: e161-e169.

Fortun K \& Fortun M (2005) Scientific Imaginaries and Ethical Plateaus in Contemporary U.S. Toxicology. American Anthropologist 107(1): 43-54.

Friedman W (1998) A Theory of Metaphors in Information Technology. In: AMCIS 1998 Proceedings, Baltimore USA, paper 278: 826-828.

Gillespie T (2010) The politics of 'platforms'. New Media \& Society 12(3): 347-364.

Greenbaum JM \& Kyng M (eds) (1991) Design at work: Cooperative design of computer systems. Hillsdale, NJ: Lawrence Erlbaum Associates, Inc.

Hanseth O, Monteiro E \& Hatling M (1996) Developing Information Infrastructures: The Tension Between Standardization and Flexibility. Science, Technology \& Human Values 21 (4): 407-426.

Hanseth O \& Ljungberg N (2001) Designing Work Oriented Infrastructures. Computer Supported Cooperative Work 18: 347-372.

Hanseth O \& Ciborra C (2007) Risk, Complexity and ICT. Chelthenham: Edward Elgar Publishing.

Hirschheim R \& Newman M (1991) Symbolism and Information Systems Development: Myth, Metaphor and Magic. Information Systems Research 2(1): 29-62.

Jæger JF \& Monteiro E (2005) Realizing organizational benefits with ICT in healthcare: the challenge of integration. Proceedings of Continuity of Care, Hels/T, Trondheim Norway, September 2005.

Jasanoff S \& Kim S-H (2009) Containing the Atom: Sociotechnical Imaginaries and Nuclear Power in the United States and South Korea. Minerva 47: 119-146.

Jasanoff S \& Kim S-H (2013) Sociotechnical Imaginaries and National Energy Policies. Science as Culture 22(2): 189-196.

Kling R (1987) Computerization as an ongoing social and political process. In: Bjerknes G, Ehn P \& Kyng M (eds) Computers and Democracy. Aldershot: Avebury, 117-136.

Kling R \& Scacchi W (1982) The web of computing: Computing technology as social organization. In: Yovits MC (ed) Advances in Computers, Vol. 21. New York: Academic Press.

Lakoff G \& Johnson M (1980) Metaphors We Live By. Chicago, IL: The University of Chicago Press.

Lampland M \& Star SL (eds) (2009) Standards and Their Stories: How Quantifying, Classifying, and Formalizing Practices Shape Everyday Life. Ithaca, NY: Cornell University Press.

Lanzara GF (1983) The Design Process: Frames, Metaphors and Games. In: Briefs U, Ciborra C \& Schneider L (eds) Proceedings of the IFIP WG 9.1 Working Conference on Systems Design For, With, and by the Users. Riva Del Sole, Italy, 1982-. Amsterdam: North-Holland Publishing Company, 29-40. 
Latour B (1990) Drawing Things Together. In: Lynch M \& Woolgar S (eds) Representation in Scientific Practice. Cambridge/London: The MIT Press, 19-68.

Leonardi PM \& Rodriguez-Lluesma C (2012) Sociomateriality as a Lens for Design: Imbrication and the constitution of technology and organization. Scandinavian Journal of Information Systems 24(2): 79-88.

Madsen KH (1989) Breakthrough by Breakdown: Metaphors and structured Domains. In: Klein K \& Kumar K (eds) Proceedings of the IFIP WG 8.2 Conference on Systems Development for Human Progress. Atlanta, GA, USA, 29-31 May 1987. Amsterdam: North-Holland Publishing Company, 41-53.

Marcus GE (ed) (1995) Technoscientific Imaginaries: Conversations, Profiles, and Memoirs. Chicago, IL: The University of Chicago Press.

Mathiassen L \& Nielsen PA (2008) Engaged scholarship in IS Research. Scandinavian Journal of Information Systems 20(2): 3-20.

Monteiro E (2001) Actor-Network Theory and Information Infrastructure. In: Ciborra C (ed) From Control to Drift: The Dynamics of Corporate Information Infrastructures. Oxford: Oxford University Press, 71-83.

Monteiro E \& Hepsø V (2002) Purity and Danger of an Information Infrastructure. Systemic Practice and Action Research 15(2): 145-167.

Monteiro E, Pollock N, Hanseth O \& Williams R (2013) From Artefacts to Infrastructures. Computer Supported Cooperative Work 22(4-6): 575-607.

Oudshoorn N, Rommes E \& Stienstra M (2004) Configuring the User as Everybody: Gender and Design in Information and Communication Technologies. Science, Technology \& Human Values 29(1): 30-63.

Otte-Trojel T, De Bont A, Aspria M, Adams S, Rundall T, Van de Klundert J \& De Mul M (2015) Developing patient portals in a fragmented healthcare system. International Journal of Medical Informatics 84(10): 835-846.

Sahay S, Monteiro E \& Aanestad M (2009) Toward a Political Perspective of Integration in Information Systems Research: The Case of Health Information Systems in India. Information Technology for Development 15(2): 83-94.

Schön DA (1996) Generative metaphor: A perspective on problem-setting in social policy. In: Ortony A (ed) Metaphor and Thought. Cambridge: Cambridge University Press, 137-163.

Star SL \& Ruhleder K (1996) Steps towards an ecology of infrastructure: borderlands of design and access for large information spaces. Information Systems Research 7(1): 111-134.

Steinhardt S \& Jackson S (2015) Anticipation Work: Cultivating Vision in Collective Practice. Proceedings of the 18th ACM Conference on Computer Supported Cooperative Work \& Social Computing, CSCW'15. Vancouver, BC, Canada, March 14-15, 2015. ACM New York, NY, USA: 443-453.

Vassilakopoulou P \& Grisot M (2014) Infrastructures for patient-centeredness: connecting novel and existing components to serve strategic agendas for change. Proceedings of the Twenty Second European Conference on Information Systems (ECIS). Tel Aviv, Israel, June 9-11, 2014.

Verran H (2001) Science and an African Logic. Chicago, IL and London: The University of Chicago Press.

Vikkelsø S (2007) Description as Intervention: Engagement and Resistance in Actor-Network Analyses. Science as Culture 16(3): 297-309.

Walsham G (1991) Organizational metaphors and information systems research. European Journal of Information Systems 1(2): 83-94.

Winthereik BR \& Vikkelsø S (2005) ICT and Integrated Care: Some Dilemmas of Standardizing Inter-Organizational Communication. Computer Supported Cooperative Work 14: 43-67. 
Winthereik BR (2010) The Project Multiple: Enactments of systems development. Scandinavian Journal of Information Systems 22(2): 49-64.

Wittgenstein L (2009) Philosophical Investigations. 4th edition. Hoboken, NJ: Wiley-Blackwell.

Woolgar S \& Neyland D (2013) Mundane Governance: Ontology and Accountability. Oxford: Oxford University Press.

Wyatt S (2004) Danger! Metaphors at Work in Economics, Geophysiology, and the Internet. Science, Technology \& Human Values 29(2): 242-261.

ZPR (2009) Zorgportaal Rijnmond.nl Project Initiatie Document - Versie 2 (Project initiation document Version 2), July 2009.

ZPR (2010) Verslag stuurgroep Zorgportaal Rijnmond d.d. 14 juni 2010 (Minutes of the meeting, ZPR Steering group) June 14, 2010.

ZPR (2011a) Verslag stuurgroep Zorgportaal Rijnmond d.d. 25 januari 2011 (Minutes of the meeting, ZPR Board) January 25, 2011.

ZPR (2011b) Agenda voor Bestuurlijk overleg Zorgportaal Rijnmond d.d. 9 februari 2011 (Minutes of the meeting, ZPR Board) February 9, 2011.

ZPR (2012) Brief aan Bestuurders, d.d. 11 april 2012 (Letter to Directors), April 11, 2012.

Zuiderent-Jerak T \& Jensen CB (2007) Editorial Introduction: Unpacking 'Intervention' in Science and Technology Studies. Science as Culture 16(3): 227-235.

Zuiderent-Jerak T (2015) Situated Intervention. Sociological experiments in health care. Cambridge, MA: The MIT Press.

\section{Notes}

1 URL: www.zorgportaalrijnmond.nl

2 Between September 2009 and August 2013 the Municipality of Rotterdam and the Dutch Ministry of Economic Affairs subsidized the ZPR project with the aim to develop a financially sustainable health portal for the Rotterdam Rijnmond region. During this early development stage, various partners in the ZPR consortium made financial investments in the project as well.

3 'Bloemetje' is a diminutive of the Dutch term 'bloem' (meaning 'flower'). In its diminutive form it bears connotations of cuteness and sympathy, which are intuitively recognized as such in the Dutch sociocultural context. In common parlance, 'bloemetje' can also denote a flower arrangement given as a gift.

4 A 'multiple socket' consists of a "block of electrical sockets that attaches to the end of a flexible cable (typically with a mains plug on the other end), allowing multiple electrical devices to be powered from a single electrical socket". See: http://en.wikipedia.org/wiki/Power_strip (accessed: 8.10.2015)

5 'To wheel in money' is a literal translation of the metaphorical expression used by the program manager.

6 Curly brackets indicate overlapping utterances.

7 The first criterion contained the items 'citizen', 'patient', 'provider', 'others'; the second 'self-reliance', 'uniformity,',communication', 'commercial activity, 'value for the region'. Items were scored with '+', '+/-', or'-'. 